Chapter 5

\title{
Physical and Technological Aspects of Solar Cells Based on Metal Oxide-Silicon Contacts with Induced Surface Inversion Layer
}

\author{
Oleksandr Malik and F. Javier De la Hidalga-W \\ Additional information is available at the end of the chapter
}

http://dx.doi.org/10.5772/53389

\section{Introduction}

With the current concerns about the worldwide environmental security, global warming, and climate change due to the emission of $\mathrm{CO}_{2}$ from the burning of fossil fuels, it is desirable to have a wide range of alternative energy technologies. Photovoltaic, or solar cells, have already proven themselves to be a viable option as a nonpolluting renewable energy source, as well as a visible business that will grow stronger in the global economy of present and future centuries.

The main problems of global practical application of solar cells for energy production are their low efficiency (typically of about 10-15\%) and the cost of photovoltaic modules $\left(\$ 200-500 / \mathrm{m}^{2}\right)$. Monocrystalline silicon is the main material for the fabrication of solar cells. It is the most studied material, and the lifetime of silicon solar cells and modules is 15-30 years. The higher efficiency of silicon solar cells (up to $24 \%$ ) that can be achieved using a complicated cell design, and applying new technological processes, lead to an undesirable increase of their total cost. From this point of view, solar cells based on more simple Schottky contacts and metal-insulator-semiconductor (MIS) structures are promising for solar energy conversion due to their relatively low production cost.

Since 1978, a new class of photovoltaic devices, namely the semiconductor-insulator-semiconductor (SIS), has emerged, using a deposited conductive top layer made of a degenerated wide-bandgap oxide semiconductor. Excellent results have been reported using tin-doped indium oxide $\left(\operatorname{In}_{2} \mathrm{O}_{3}: \mathrm{Sn}\right.$ or ITO). Other oxide semiconductors, such as fluorine-doped tin oxide $\left(\mathrm{SnO}_{2}: \mathrm{F}\right)$ and doped zinc-oxide $(\mathrm{ZnO})$, have also been used as a transparent conducting electrode. 
Thin films of these oxides behave as a metal, thus such SIS structures present electrical properties similar to those presented by MIS devices. Of course, the optical and photoelectrical properties of SIS structures exceed the properties of MIS devices.

In our chapter of the book "Solar Energy", edited by Radu D. Rugescu [1], the reader can find a complete bibliography regarding the SIS solar cells and the properties of transparent conducting oxides fabricated using different methods.

In that book, a preceding discussion regarding the fabrication process of SIS solar cells, the structural, electrical and optical properties of ITO and $\mathrm{SnO}_{2}: \mathrm{F}$ thin films, as well as the physical model of spray deposited ITO-Si solar cells and theirs properties has been presented. It was shown that such structures present a high barrier height that is not typical for Schottky diodes. The authors developed a physical model of the ITO-Si solar cells based on an inversion p-n junction similar to that reported by J. Shewchun et al. [2] for MIS structures with an $\mathrm{Al}$ electrode. According to this model, the I-V characteristics are dominated by a diffusion current flow in the bulk of the silicon substrate and show the usual behavior for a Shockley diode.

The aim of this chapter is to discuss some new physical aspects of spray deposited ITO-Si solar cells which are tightly connected with the fabrication technology. Below, we will show that suitable process schedules for chemical treatment of the silicon surface with the presence of acceptor-type surface states, is the reason for the inversion of the conductivity type at the silicon surface. A sufficiently high potential barrier can be formed before the deposition of the ITO film if a minimum amount of fixed charge appears within the interfacial layer very close to the silicon surface. Then the role of the ITO electrode is the formation of an ohmic contact on the inversion layer.

\section{Barrier height of MIS solar cells}

Solar cells based on contact metal-semiconductor with a Schottky barrier really represent MIS structures due to the existence of a thin insulator layer between the metal and the semiconductor. MIS solar cells are receiving increasing attention because they present several inherent advantages such as low cost, high yield, fabrication at low substrate temperature, etc. However, one drawback of such cells is that their open-circuit voltage is slightly low and depends on the potential barrier height.

The expression to calculate the barrier height $\phi_{B n}$ for $\mathrm{n}$-type substrates is given by [3]

$$
\phi_{B n}=\gamma\left(\phi_{m}-\chi_{s}\right)+(1-\gamma)\left(E_{g}-\phi_{0}\right)-\left(\frac{1-\gamma}{D_{s}}\right) \frac{Q_{o x}}{q}
$$

where 


$$
\gamma=\left(1+\frac{q \delta D_{s}}{\varepsilon_{i}}\right)^{-1}
$$

Here, $\phi_{m}$ is the metal work function, $\chi_{s}$ is the semiconductor electron affinity, $E_{g}$ is the semiconductor energy gap, $\phi_{0}$ is energy level of surface states at the semiconductor surface, $\delta$ is insulator (oxide) thickness, $D_{s}$ is density of surface states, and $\frac{Q_{o x}}{q}$ represents the amount of fixed charge lying within the interfacial layer very close to the insulator-semiconductor interface; the other symbols have their usual meaning. Figure 1 shows the calculated variation of the barrier height with the metal work function for different values of interfacial layer thickness [3]

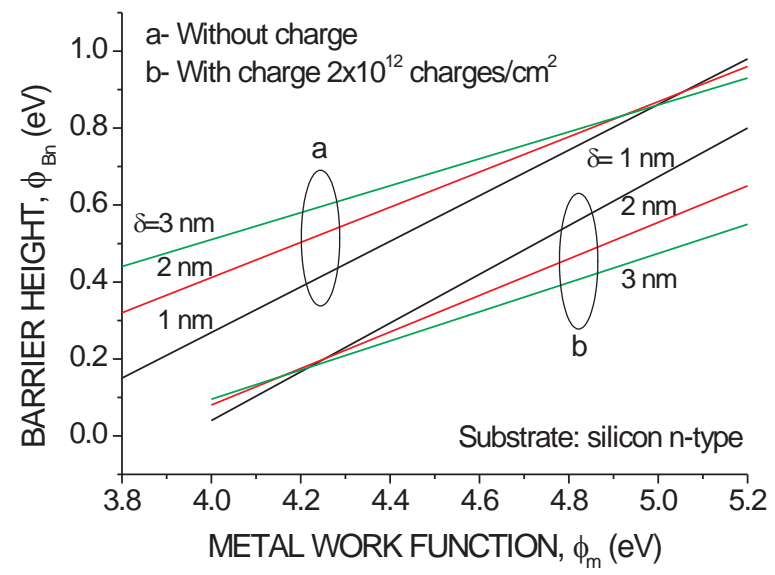

Figure 1. Calculated variation of the barrier height with metal work function for different values of the interfacial layer thickness [3].

These calculations were conducted assuming $D_{s}=3 \times 10^{12}$ states $/ \mathrm{cm}^{2} / \mathrm{eV}$ and $\phi_{0}=0.27 \mathrm{eV}$ for silicon. Positive oxide (insulator) charge was fixed to $2 \times 10^{12}$ charges $/ \mathrm{cm}^{2}$. The positive sign of the charge is typical for several chemical methods used for the fabrication of thermal thin oxide on the silicon surface. It is clear that the existence of this charge decreases the barrier height even if the metal work function is as high as $5.2 \mathrm{eV}$; for this case, the barrier height does not exceed $0.8 \mathrm{eV}$.

Another situation becomes apparent when the fixed charge is negative, for example, in presence of acceptor-like surface states. In this case the sign of the third term in equation (1) is positive, and a higher value of the barrier height is possible. Thermally grown oxide on the silicon surface usually presents a positive fixed charge, however it may be possible to intro- 
duce a negative charge in the oxide by developing suitable process schedules for the chemical treatment of the semiconductor surface.

\section{Relation between the charge and surface potential}

For our discussion, we must find a relationship between the charge on the semiconductor surface $Q_{s}$ and the surface potential $\phi_{s}$. Considering a semiconductor having donor and acceptor impurities $N_{\mathrm{d}}$ and $N_{\mathrm{a}}$ respectively, completely ionized at room temperature, we need to solve the Poisson equation

$\frac{d^{2} \varphi}{d x^{2}}=-\frac{4 \pi \rho}{\varepsilon} ; \rho=q\left[N_{d}-N_{a}+p(x)-n(x)\right]$.

Using the boundary conditions:

$\varphi=\varphi_{s} \triangleleft 0 \quad$ at $x=0$,

$\varphi \rightarrow 0, \quad d \varphi / d x \rightarrow 0 \quad$ at $x \rightarrow \infty$.

In the semiconductor volume we consider charge neutrality:

$N_{d}+p=n+N_{a^{\prime}}$

where $p$ and $n$ are the concentrations of electrons and holes, respectively, and

$n(x)=n \exp (q \varphi / k T), \quad p(x)=p \exp (-q \varphi / k T)$.

Defining $n / n_{i}=n_{i} / p=\gamma$ and $\psi=q \varphi / k T$.

Then the Poisson equation can be written as

$\frac{d^{2} \psi}{d x^{2}}=-\frac{4 \pi q^{2} n_{i}}{\varepsilon k T}\left[\gamma(1-\exp \psi)+\gamma^{-1}(\exp (-\psi)-1]\right.$

After integrating both sides with respect to $\psi$ and determining the integration constant from the boundary conditions: $\psi \rightarrow 0$ and $d \psi / d x \rightarrow 0$ at $x \rightarrow \infty$

$\left(\frac{d \psi}{d x}\right)^{2}=L_{D}^{-2}\left[\gamma(\exp \psi-1)+\gamma^{-1}(\exp (-\psi)-1)+\psi\left(\gamma^{-1}-\gamma\right)\right]$

Where $L_{D}^{-2}=8 \pi q^{2} n_{i} / \varepsilon k T$, and $n_{\mathrm{i}}$ is the intrinsic carrier concentration.

It is easy to obtain a differential equation for the potential $\phi$ in the form

$\frac{d \phi}{d x}=-\left(k T / q L_{D}\right)\left[\gamma\left(\exp \left(\frac{q \phi}{k T}\right)-1\right)+\gamma^{-1}\left(\exp -\left(\frac{q \phi}{k T}\right)-1\right)+\frac{q \phi}{k T}\left(\gamma^{-1}-\gamma\right)\right]^{1 / 2}$

At $x=0$, the boundary condition is $\varepsilon E_{x=0}=4 \pi Q_{s^{\prime}}$

Where $E_{x=0}=-d \phi / d x$, and $E_{x=0}$ is electric field at the surface of the semiconductor.

Finally, we obtain 


$$
Q_{s}=2 q n_{i} L_{D}\left[\gamma\left(\exp \left(\frac{q \varphi_{s}}{k T}\right)-1\right)+\gamma^{-1}\left(\exp -\left(\frac{q \varphi_{s}}{k T}\right)-1\right)+\frac{q \varphi_{s}}{k T}\left(\gamma^{-1}-\gamma\right)\right]^{1 / 2}
$$

Here, $\varphi_{s} \triangleleft 0$, and $Q_{s}$ is a positive charge. For an n-type semiconductor, a band bending will be developed due to the accumulation of electrons at the semiconductor surface.

For a negative charge $Q_{s}$, we need to change the sign of $\varphi_{s}$ in equation (3).

Figure 2 shows the calculated dependences of the negative $Q_{s}$ on the surface potential at the silicon surface for different concentrations of donors in the silicon substrate.

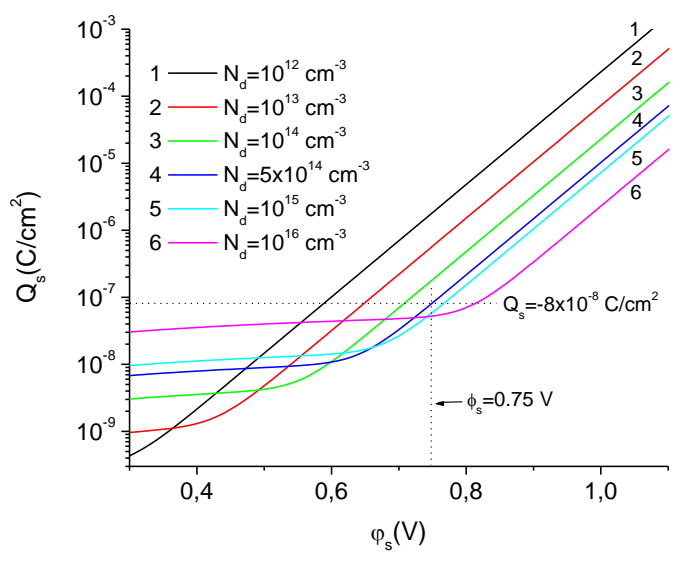

Figure 2. Calculated dependence of $Q_{S}$ on the surface potential at the silicon surface for different donor concentrations in the silicon substrate.

We will discuss the properties of solar cells fabricated on n-type silicon with $N_{\mathrm{d}}=5 \times 10^{14} \mathrm{~cm}^{-3}$. If a negative charge $Q_{s}=8 \times 10^{-8} \mathrm{C} / \mathrm{cm}^{2}$ is present on the Si surface, the surface potential $0.75 \mathrm{eV}$ is due to the strong inversion condition because $q \varphi_{s}>2\left(E_{F}-E_{i}\right)=0.28 \mathrm{eV}$, where $E_{F}$ and $E_{i}$ are the Fermi and intrinsic energy levels in the silicon substrate, respectively.

\section{Surface potential of the silicon wafers after a chemical cleaning}

For any technical application, the silicon wafer must be subjected to a certain schedule of chemical treatment. These are very important technological steps necessary to prevent the contamination of the future device from non-controlled sources such as some metals that can introduce deep energy levels into the substrate.

The RCA Standard Cleaning, developed by W. Kern and D. Puotinen in 1965, and disclosed in 1970, is extremely effective for removing contamination from silicon surfaces, and it is a 
current industry standard. The RCA cleaning has two sequential steps: the Standard Cleaning 1 (SC-1), followed by Standard Cleaning 2 (SC-2): The SC-1 solution, consisting of a mixture of ammonium-hydroxide $\left(\mathrm{NH}_{4} \mathrm{OH}\right)$, hydrogen-peroxide $\left(\mathrm{H}_{2} \mathrm{O}_{2}\right)$, and water $\left(\mathrm{H}_{2} \mathrm{O}\right)$, is the most efficient particle removing agent found to date. This mixture is also referred to as the Ammonium-Hydroxide/Hydrogen-Peroxide Mixture (APM).

In the SC-1 cleaning solution, the formation of native oxide $\left(\mathrm{SiO}_{2}\right)$ by hydrogen peroxide and the etching of the silicon oxide by alkalis $\left(\mathrm{NH}_{4} \mathrm{OH}\right)$ operate simultaneously. For this reason, the overall wafer thickness is slowly reduced, but certain thickness of $\mathrm{SiO}_{2}$ forms on the wafer surface. In the past, the SC-1 solution presented a tendency to deposit metals on the surface of the wafers, and consequently a treatment with the SC-2 mixture $\left(\mathrm{H}_{2} \mathrm{O}: \mathrm{HCl}: \mathrm{H}_{2} \mathrm{O}\right)$ were necessary to remove metals.

It is possible to consider SC-1 and SC-2 solutions as agents for wet chemical oxidation of the silicon wafer due to the formation of a thin silicon dioxide layer during the treatment of the wafer in these solutions. Other chemical agents such as $\mathrm{HCl}, \mathrm{HNO}_{3}$, the $\mathrm{H}_{2} \mathrm{SO}_{4}: \mathrm{H}_{2} \mathrm{O}_{2}$ mixture, hydrogen-peroxide $\left(\mathrm{H}_{2} \mathrm{O}_{2}\right)$, and water $\left(\mathrm{H}_{2} \mathrm{O}\right)$, can also be used for wet chemical oxidation. With a suitable thickness and physical parameters, these oxide layers can be used for the fabrication of MIS solar cells. However, the question is what the thickness of the silicon oxide layer will be obtained and which surface potential on the wafer will be developed after applying this technological procedure? One more question is connected with the density of surface states after the wet chemical oxidation.

Many researchers have tried to find the answer to these questions. For instance, a complete investigation on this issue was conducted by Angermann [4]; some parameters of the oxide layers formed with different chemical agents are shown in Table 1.

\begin{tabular}{|c|c|c|c|c|c|}
\hline Oxidizing solutions & Composition & $\mathrm{T}\left[{ }^{0} \mathrm{C}\right]$ & $\begin{array}{l}\text { Treatment time } \\
\text { (min) }\end{array}$ & $\begin{array}{c}D_{i t, \min } \\
{\left[\times 10^{12} \mathrm{~cm}^{-2} \mathrm{eV}^{-1}\right]}\end{array}$ & $<\mathrm{d}_{\mathrm{ox}}>[\mathrm{nm}]$ \\
\hline SC-1 & $6: 1: 1$ & 75 & 10 & 6 & 1.1 \\
\hline SC-2 & $5: 1: 1$ & 75 & 10 & 5 & 1.3 \\
\hline $\mathrm{SC}-1+\mathrm{SC}-2$ & - & 75 & $10+10$ & 6 & 1.2 \\
\hline $\mathrm{H}_{2} \mathrm{SO}_{4}: \mathrm{H}_{2} \mathrm{O}_{2}$ & $1: 1$ & 120 & 5 & 5 & 1.8 \\
\hline $\mathrm{HCl}$ & $36 \%$ & 40 & 5 & 3 & - \\
\hline $\mathrm{HNO}_{3}$ & $65 \%$ & 60 & 5 & 8 & - \\
\hline Deonized $\mathrm{H}_{2} \mathrm{O}$ & $18 \mathrm{M} \Omega-\mathrm{cm}$ & 80 & 120 & 0.4 & $\begin{array}{l}1.5 \mathrm{Si}(111) \\
2.5 \mathrm{Si}(100)\end{array}$ \\
\hline
\end{tabular}

Table 1. Parameters of the oxide layer formed with different chemical agents [4], $D_{i t \text { min }}$ is the minimum density of surface states. 
Other published results $[5,6]$ present a thickness of the oxide in the range of $0.8-1 \mathrm{~nm}$ after treatment in SC-1 solution. From Table1 it is clear that the best result regarding the minimum density of surface states is obtained by using hot water. With other chemical agents $\mathrm{D}_{\mathrm{it} / \text { min }}$ exceeds the value of $10^{12} \mathrm{~cm}^{-2} \mathrm{eV}^{-1}$. After etching in $\mathrm{NH}_{4} \mathrm{~F}$ during $6.5 \mathrm{~min}$, the oxide thickness obtained with the SC-1 solution decreases to $0.3 \mathrm{~nm}$, and the density of surface states is $1 \times 10^{11} \mathrm{~cm}^{-2} \mathrm{eV}^{-1}$. Such parameters are suitable for the fabrication of Schottky diodes based on metal-semiconductor structures.

Now, it is interesting to know the band bending of the silicon surface after different processes for obtaining the chemical grown oxide. Again, and according to reference [4], the position of the Fermi level $E_{F s}=E_{F}-E_{i}$ (at $\mathrm{x}=0$ ), determined at the n-type Si surface, with bulk Fermi level $E_{f b}=E_{F}-E_{i}(x>0)=-0.32 \mathrm{eV}$, after $\mathrm{HF}$ and $\mathrm{NH}_{4} \mathrm{~F}$ and subsequent wet chemical oxidation in various solutions, is shown in table 2 .

\begin{tabular}{|c|c|c|c|c|c|c|c|}
\hline \multicolumn{8}{|c|}{ Chemical etching Wet chemical oxidation agent } \\
\hline $\mathrm{HF}$ & $\mathrm{NH}_{4} \mathrm{~F}$ & SC-1 & SC-2 & $\mathrm{H}_{2} \mathrm{SO}_{4} / \mathrm{H}_{2} \mathrm{O}_{2}$ & $\mathrm{HCl}$ & $\mathrm{HNO}_{3}$ & $\mathrm{H}_{2} \mathrm{O}$ \\
\hline+0.32 & $-0.02 /+0.1$ & -0.25 & +0.1 & -0.03 & +0.18 & +0.2 & $\cong 0$ \\
\hline
\end{tabular}

Table 2. Fermi level position $E_{F s}=E_{F}-E_{i}($ at $\mathrm{x}=0)$ determined on $\mathrm{n}$-type Si surfaces when the bulk Fermi level is $E_{f b}=E_{F}-E_{i}$ $(x>0)=-0.32 \mathrm{eV}$, after $\mathrm{HF}$ and $\mathrm{NH}_{4} \mathrm{~F}$, and subsequent wet chemical oxidation in various solutions.

The HF treatment leads to a strong inversion layer on H-terminated p-type silicon surfaces, which results from a positive charge induced by electronegative surface groups $(-\mathrm{H},-\mathrm{O}-\mathrm{H}$, and $-\mathrm{F}$ ) on the surface silicon atoms. Using $\mathrm{NH}_{4} \mathrm{~F}$ as the final etching agent under cleanroom conditions, the remaining amount of surface charges results from the electro-negativity difference between silicon and hydrogen.

After the wet-chemical oxidation of initially $\mathrm{H}$-terminated surfaces, characteristic values of the surface Fermi-level $E_{F s}$ as shown in Table 2, were obtained from the interface-trapped charge and from different kinds of oxide charges.

Most of the oxidizing solutions $\mathrm{SC}-2, \mathrm{HCl}$, and $\mathrm{HNO}_{3}$ cause a strong depletion of holes on ptype silicon surfaces due to the positive fixed oxide charge, which is also known from $\mathrm{CV}$ measurements of thermally grown oxides.

In contrast, the SC-1 process causes a negative surface charge, which is possible to originate from the dissociation of $\equiv \mathrm{Si}-\mathrm{OH}$ groups of the oxide layer in the alkaline solution $(\equiv \mathrm{Si}-\mathrm{OH} \Leftrightarrow$ $\left.\equiv \mathrm{Si}-\mathrm{O}^{-}+\mathrm{H}^{+}\right)$.

From this reported results we make an important conclusion regarding the use of an n-type silicon substrate: the forming of transparent for carriers insulating layer after wet oxidation and the formation of a depletion or inversion layer on the silicon surface after substrate treatment in the SC-1 solution. All other treatments in wet oxidizing solutions will produce an accumulation band bending. 


\section{Chemical oxide after treatment in hydrogen-peroxide}

The chemical oxide can also be created on the silicon surface with the treatment of the wafer in an aqueous solution of hydrogen-peroxide. Neuwald et al. [7] shown that a very thin (about $0.5 \mathrm{~nm}$ ) oxide is formed after immersion of a (111) silicon wafer in ultrapure $30 \%$ $\mathrm{H}_{2} \mathrm{O}_{2}$ solution. XPS analysis shows that the oxide thickness saturates on this level after 10 minutes of immersion in the solution. Other results published by Verhaverbeke et al. [8] discuss in detail the limitation of the oxide thickness obtained in $\mathrm{H}_{2} \mathrm{O}_{2}$ and SC- 1 solutions. They show that the oxide thickness obtained in $\mathrm{H}_{2} \mathrm{O}_{2}$ solutions for different concentrations as function of time does not exceed $0.9 \mathrm{~nm}$. In order to explain this experimental fact they used the results of Stoneham and Tasker, where the effect of image charges and their influence on the grown oxide films are studied. These authors found that the polarization energies associated with localized charges near the interface between oxides and silicon provide a driving force, over short distances, which affect the transport of peroxide anions $\mathrm{HO}_{2}^{-}$(principal oxidant) to the silicon surface. As the oxide thickness grows, the image charge reduces the transport of the ionic species, and the oxidation process is limited. According to Verhaverbeke, the model based on the charge transport (Figure 3) that predicts the frequently observed limitation of an oxide thickness of around $0.8-1 \mathrm{~nm}$, may also be applied to the oxide grown in SC-1 solutions with a certain content of hydrogen-peroxide. It is not possible to know in advance the sign of the charge in the oxide formed with ultrapure $\mathrm{H}_{2} \mathrm{O}_{2}$, but below we show that the presence of some impurities in the hydrogen-peroxide solution can change drastically the situation.

Solution Oxide Silicon

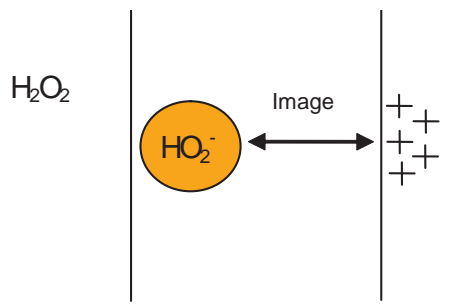

Figure 3. Schematic illustration of Image Charge transport in $\mathrm{H}_{2} \mathrm{O}_{2}$ and SC-1 solutions [8].

\section{Chemical oxide fabricated with a contaminated SC-1 solution}

Generally, silicon wafers always present some charge in either, chemically or thermally grown native oxide. It is well known that a fixed positive charge appears on thermally oxidized Si wafers. It is also known that a large positive fixed oxide charge appears in naturally 
oxidized Si wafers soon after they are dipped in an aqueous hydrofluoric acid (HF), and then the charge decreases as the native oxide grows in air. Munakata and Shimizu $[9,10]$ reported that when silicon wafers are rinsed by an SC-1 solution, a fairy large negative charge of $5.8 \times 0^{11}$ charges $/ \mathrm{cm}^{2}$ is observed in commercially available n-type Si wafers. In this case, the wafers were rinsed with the SC- 1 solution in a Pyrex glass container. The charge was significantly smaller when the treatment was conducted using a quartz container; this is because the $\mathrm{Al}$ (and also $\mathrm{Fe}$ ) concentration in quartz is generally more than one order of magnitude lower than that found in Pyrex glass. This fact clearly suggests that some species in the SC-1 solution must be the cause of the negative charge, whose density should be much higher than that of the positive fixed oxide charge. At this moment, the exact chemical mechanism of the negative charge formation is not clear. Authors assumed that the negative charge arises from ( $\mathrm{AlSiO})^{-}$networks, when 3-valence $\mathrm{Al}$ substitutes 4-valence $\mathrm{Si}$ in the oxide. The role of $\mathrm{Al}$ to form the negative oxide charge on the Si surface after rinsing with the SC-1 solution was verified with especially Al-contaminated SC-1 solutions. The same results were also obtained using 3-valence iron (Fe)-contaminated solutions.

It is known that $\mathrm{Al}$ atoms can isomerically substitute the $\mathrm{Si}$ atoms forming a wide class of $\left(\mathrm{SiO}_{2}\right)_{x} \times\left(\mathrm{Al}_{2} \mathrm{O}_{3}\right)_{\mathrm{y}}$, and $\mathrm{Al}$ can penetrate in the $\mathrm{SiO}_{2}$ film at a depth of about $100 \mathrm{~nm}$. The $\mathrm{Al}$ atoms in the $\mathrm{SiO}_{2}$ film break partially or completely the $\mathrm{d} \pi-\pi \sigma$ bounds. In three-coordinated states, these atoms are strong acceptors of electrons.

We assume that the negative charge can also appear in oxides obtained using $\mathrm{Al}$ (or Fe)-contaminated hydrogen-peroxide $\left(\mathrm{H}_{2} \mathrm{O}_{2}\right)$ solutions.

\section{Work function of tin-doped indium oxide (ITO) films}

In this section we discuss the work function $\left(q \phi_{\text {ITO }}\right)$ of the ITO film. The data about the value of $q \phi_{\text {ITO }}$ is not presented systematically in the literature. This parameter presents a strong dependence on the fabrication method, structure and morphology of the film, and also on the carrier concentration. Reported results for films obtained by thermal evaporation give a work function of $5.0 \mathrm{eV}$ [11]. The work function of pure $\mathrm{In}_{2} \mathrm{O}_{3}$ films obtained by RF magnetron sputtering was found to be in the range of 5.3-5.4 eV [12], and in contrast, the work function of ITO films with 5-20 wt. \% Sn was found in the 4.6-4.8 eV range.

The work function of the ITO films fabricated by pyrosol technique was reported around 4.8 $\mathrm{eV}$, without an additional thermal treatment, whereas it was around $5.2 \mathrm{eV}$ after a thermal treatment [13].

In the case of n-type degenerated semiconductors, such as the ITO films, the work function is expected to shift when the carrier concentration $n_{e}$ changes. It is inversely proportional to $n_{e}^{2 / 3}$; nevertheless, an opposite trend has been found for the relationship between the optical energy gap $E_{\mathrm{g}}{ }^{\text {opt }}$ and $n_{e}$. The Fermi energy in the film conduction band should vary for an increasing or decreasing $n_{e}$. Therefore, the control of the work function with $n_{e}$ in the ITO layers is an important issue to take into account for the estimation of the energy barriers in 
Schottky and MIS devices. According to Sato et al. [14], the optical band gaps of the ITO films deposited by dc magnetron sputtering increased from 3.8 to $4.3 \mathrm{eV}$ when the carrier density increased from $8.8 \times 10^{19}$ to $8.2 \times 10^{20} \mathrm{~cm}^{-3}$, whereas the work function decreased from 5.5 to $4.8 \mathrm{eV}$. The variation of the optical band gap $\left(E_{g}{ }^{o p t}\right)$ and the work function $(\phi)$, as a function of the two-thirds power of the carrier density $\left(n_{e}^{2 / 3}\right)$ for undoped $\operatorname{In}_{2} \mathrm{O}_{3}$ and ITO films, is shown in Figure 4.

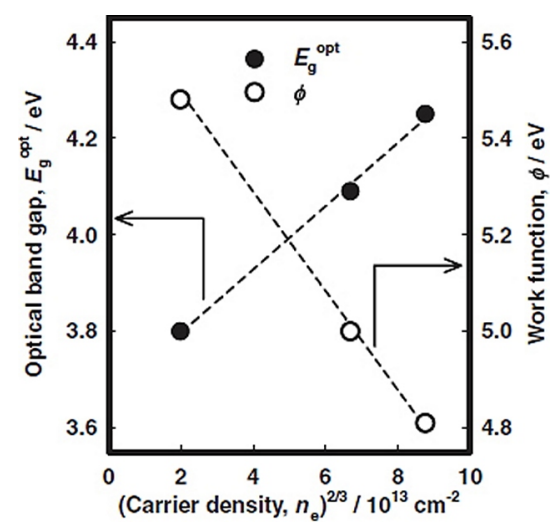

Figure 4. Variation of the optical band gap $\left(E_{g}{ }^{o p t}\right)$ (solid circles) and the work function $(\phi)$ (open circles) as a function of the two-thirds power of the carrier density $\left(n_{e}^{2 / 3}\right)$ for undoped $\ln _{2} \mathrm{O}_{3}$ and ITO films [14].

For our solar cell we are using Sn-doped indium oxide films (ITO) fabricated by spray pyrolysis technique. The optimized films have a carrier concentration of about $10^{21} \mathrm{~cm}^{-3}$, and the shift of the Fermi level is about $0.5 \mathrm{eV}$. Taking into account the reported data about the work function, we will use $q \phi_{\text {ITO }}=4.8 \mathrm{eV}$.

\section{Fabrication of ITO and FTO films by spray pyrolysis}

The spray pyrolysis technique was employed for the deposition of thin ITO and FTO films on glass and sapphire substrates in order to investigate their structural, electric, and optical properties. A $10 \Omega$-cm n-type (100)-silicon substrate, chemically cleaned and specially treated, was used for the fabrication of solar cells. The apparatus (atomizer) for the spray deposition was designed for obtaining small-size droplets. The substrates were mounted on a heater covered with a carbon disc for obtaining uniform temperature. Spraying was made using compressed air. Periodical cycles of the deposition with duration of $1 \mathrm{sec}$ and intervals of $5 \mathrm{sec}$ were employed to prevent a rapid substrate cooling. The deposition rate was high, of about $200 \mathrm{~nm} / \mathrm{min}$. For the ITO films deposition, $13.5 \mathrm{mg}$ of $\mathrm{InCl}_{3}$ were dissolved in a 170 $\mathrm{ml}$ mixture of ethylic alcohol and water in a 1:1 proportion, and adding $5 \mathrm{ml}$ of $\mathrm{HCl}$. The different ratios of $\mathrm{Sn} / \mathrm{In}$ achieved in the ITO films were controlled by adding in the solution a calculated amount of tin chloride $\left(\mathrm{SnCl}_{4}{ }^{*} 5 \mathrm{H}_{2} \mathrm{O}\right)$. The substrate temperature, in the range of 
$380-480^{\circ} \mathrm{C}$, was controlled using a thermocouple with an accuracy of $\pm 5^{\circ} \mathrm{C}$. The optimum distance from the atomizer to the substrate and the compressed air pressure were $25 \mathrm{~cm}$ and 1.4 $\mathrm{kg} / \mathrm{cm}^{2}$, respectively. Figure 5 shows schematically the equipment set-up.

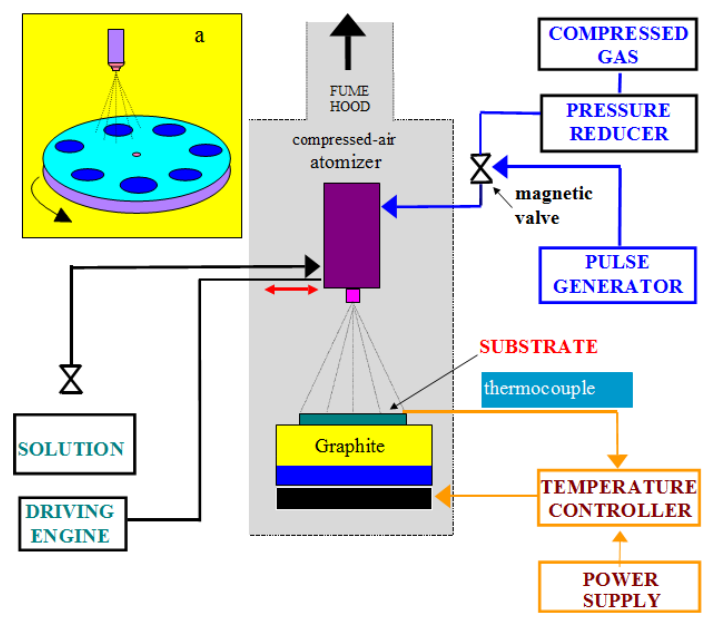

Figure 5. Set-up of the equipment used for the deposition of the ITO films. Insert (a) shows the modification of the equipment for the purpose of mass-production.

\section{Characterization equipment and methods}

The film thickness was measured with an Alpha Step 200 electronic profilometer. The electrical resistivity, Hall mobility and carrier concentration were measured at room temperature using the van der Pauw method. Hall effect parameters were recorded for a magnetic field of 0.25 Tesla. The optical transmission spectrum was obtained using a spectrophotometer. The structural characterization was carried out with an X-ray diffractometer operating in the Bragg-Brentano $\Theta-\Theta$ geometry with $\mathrm{Cu} \mathrm{K}$ radiation. A JSPM 5200 atomic force microscope was used to study the film surfaces. The chemical composition of the films was determined using an UHV system of VG Microtech ESCA2000 Multilab, with an Al- $\mathrm{K}_{\alpha}$ X-ray source $(1486.6 \mathrm{eV})$ and a CLAM4 MCD analyzer.

\section{Properties of the spray deposited ITO films}

The X-ray diffraction (XRD) measurements shown in Figure 6 indicate that all deposited ITO films, with thicknesses in the 160-200 nm range, and fabricated from the chemical solutions for different $\mathrm{Sn} / \mathrm{In}$ ratios, presents a cubic bixebyte structure in a polycrystalline configuration with (400) as the preferential grain orientation 


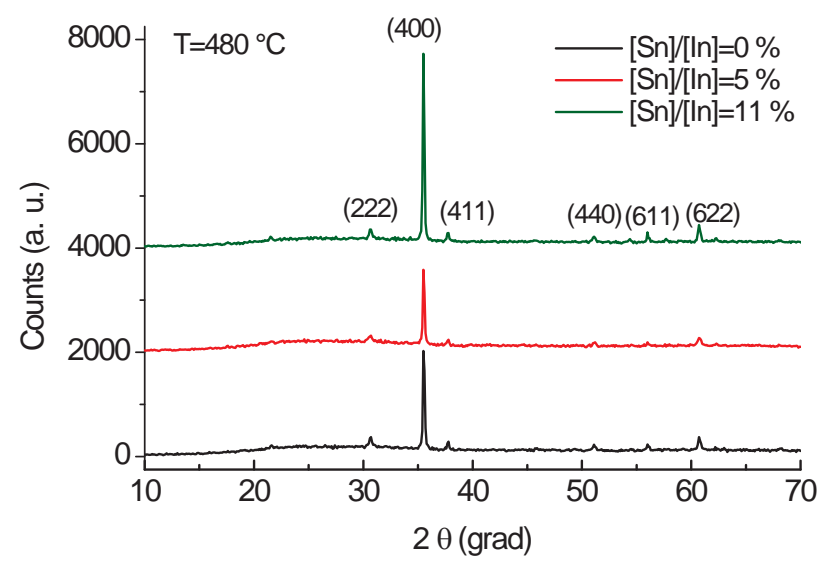

Figure 6. XRD spectra of the ITO films fabricated using precursors with different Sn/In ratios. The mean size of the grains, 30-50 nm, was determined using the classical Debye-Scherrer formula from the half-wave of the (400) reflections of the XRD patterns.

A surface roughness of about $30 \mathrm{~nm}$ was determined from images of the film surfaces obtained with an atomic force microscope (Figure 7).
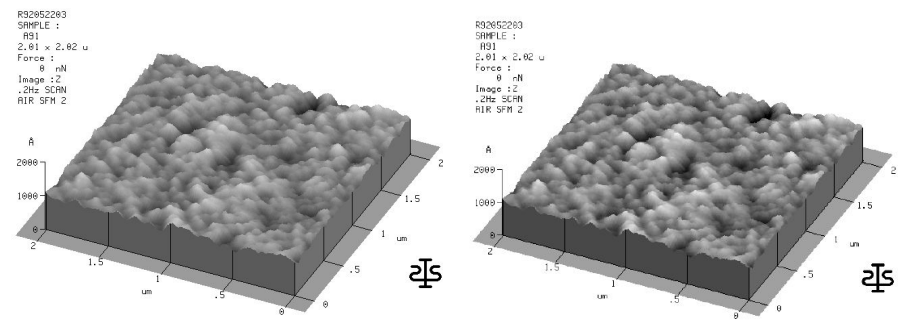

Figure 7. Atomic force images of the $\ln _{2} \mathrm{O}_{3}$ film (left) and the ITO film with $5 \% \mathrm{Sn} / \mathrm{ln}$ (right).

Figures 8 and 9 show the dependence of the electric parameters of deposited ITO film on the ratio $\mathrm{Sn} / \mathrm{In}$ used in the solution for the fabrication of the films. The sheet resistance $R_{s}$ shown in Figure 8 has a minimum $12 \Omega / \square$ for the films prepared using a solution with $5 \% \mathrm{Sn} / \mathrm{In}$ ratio.

The minimum resistivity obtained for the films deposited with a $5 \% \mathrm{Sn} / \mathrm{In}$ solution is $2 \times 10^{-4}$ $\Omega-\mathrm{cm}$. The variation of carrier concentration as a function of the $\mathrm{Sn} / \mathrm{In}$ ratio in the precursors is shown in Figure 9. The carrier concentration presented a value of $1.1 \times 10^{21} \mathrm{~cm}^{-3}$ at the $5 \%$ $\mathrm{Sn} / \mathrm{In}$ ratio. This high value is comparable with better results achieved when other technological methods are used for the fabrication of the ITO thin films. 


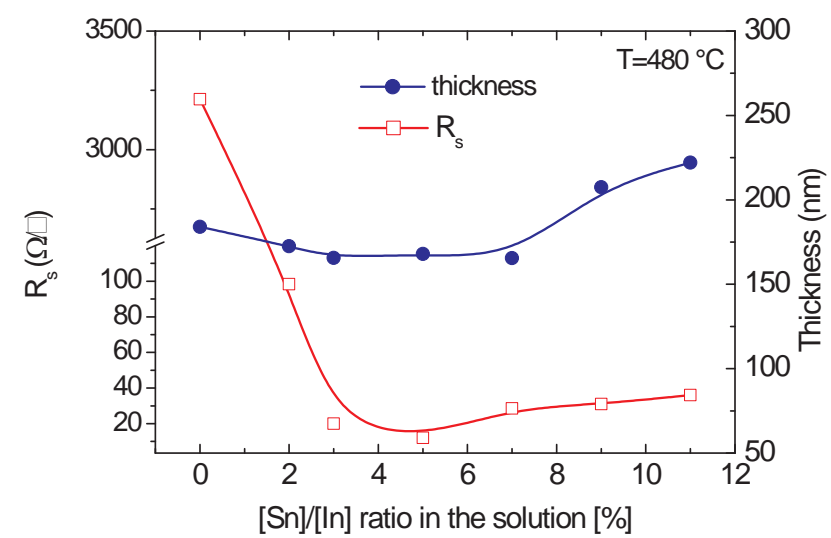

Figure 8. The sheet resistance as a function of the $\mathrm{Sn} / \mathrm{In}$ ratio in the precursor used for the film deposition. The thicknesses of the films are also shown.

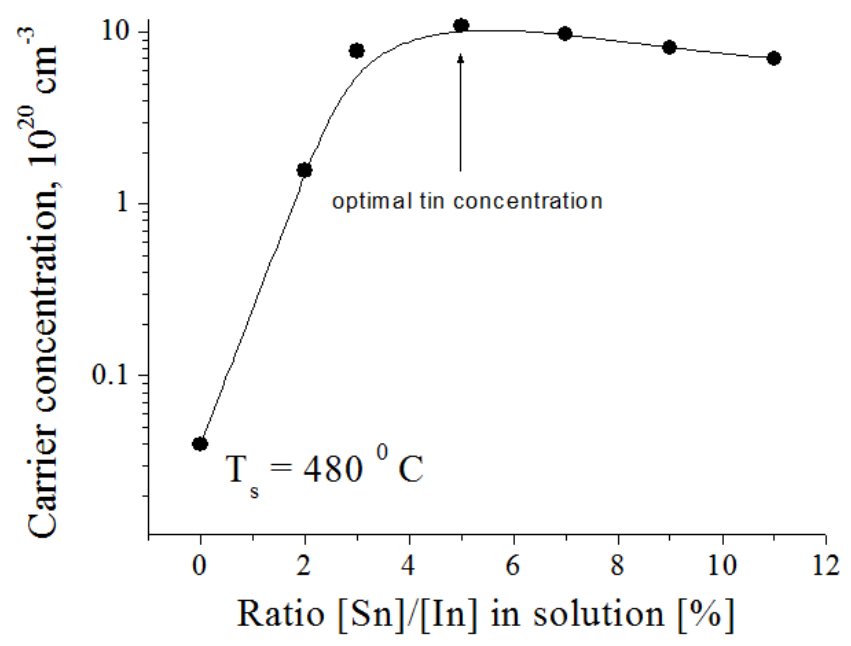

Figure 9. Variation of the carrier concentration as a function of the $\mathrm{Sn} / \mathrm{In}$ ratio.

The optical transmission of indium oxide films for two thicknesses deposited on glass substrates, as a function of the wavelength, is shown in Figure 10. 


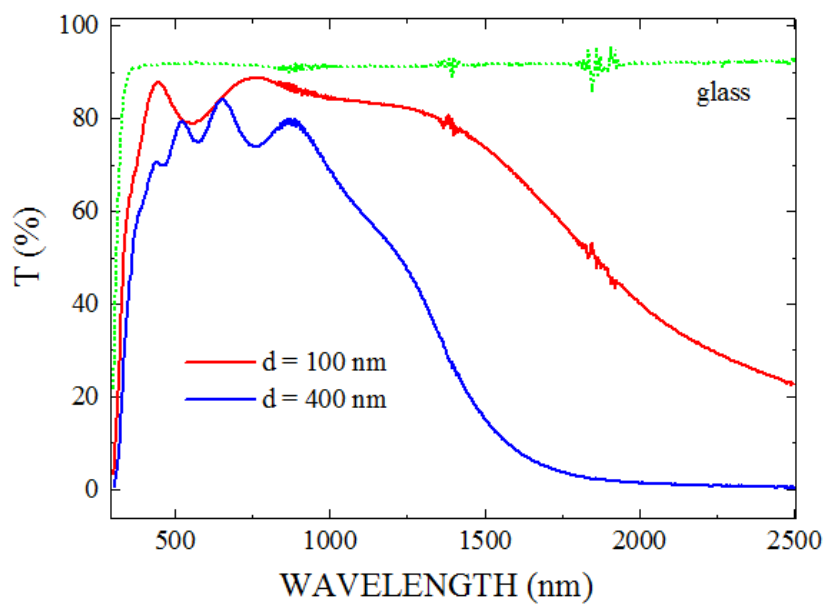

Figure 10. Optical transmission of the ITO films for two thicknesses as a function of the wavelength

The use of sapphire substrates allows for determining the optical energy gap of the ITO films by the extrapolation of the linear part of the $\alpha^{2}(h v)$ curves to $\alpha^{2}=0$, where $\alpha$ is the absorption coefficient. The optical gap increases with the carrier concentration due to the well known Moss-Burstein shift. For ITO films fabricated using the solution with a 5\% Sn/In ratio, this shift is $0.5 \mathrm{eV}$, and the optical gap is $4.2 \pm 0.1 \mathrm{eV}$. Such high value of the optical gap offers transparency in the ultraviolet range, which is of fundamental importance in solar cell applications. Because of the opposite dependence of conductivity $(\sigma)$ and transmission $(T)$ of the ITO film on its thickness $(t)$, both parameters must be optimized. A performance comparison of different films is possible using $\phi_{T C}=T^{10} / R_{S}=\sigma t \exp (-10 a t)$ as a figure of merit [21]. Table 3 compares the values of $\phi_{T C}$ for spray deposited ITO films reported in this work with some results obtained by other authors but using a different deposition technique.

\begin{tabular}{|c|c|c|c|c|}
\hline Process & $R_{s} \Omega / \square$ & $T(\%)$ & $\phi_{T C,}\left(\Omega^{-1}\right) \times 10^{-3}$ & Reference \\
\hline spray & 26.0 & 90 & 13.4 & [15] \\
\hline spray & 9.34 & 85 & 21 & [16] \\
\hline spray & 10.0 & 90 & 34.9 & [17] \\
\hline spray & 4.4 & 85 & 44.7 & [18] \\
\hline sputtering & 12.5 & 95 & 47.9 & [19] \\
\hline evaporation & 25.0 & 98 & 32.6 & [20] \\
\hline spray & 12.0 & 93.7 & 43.5 & [1] and this work \\
\hline
\end{tabular}

Table 3. Comparison of the values of $\phi_{T C}$ for the ITO films 


\section{Solar cells fabrication}

Solar cells were fabricated using (100) n-type (phosphorous doped) single-crystal silicon wafers of $10 \Omega$-cm resistivity. Both sides of the wafer were polished. Standard wafer cleaning procedure was used. In order to form the barrier, an $80 \mathrm{~nm}$ ITO film with a sheet resistance of $30 \Omega / \square$ was deposited by spray pyrolysis on the silicon substrate treated in $\mathrm{H}_{2} \mathrm{O}_{2}$ or SC-1 heated solutions during 10 minutes. The ITO thickness was chosen for an effective antireflection action of the ITO film as shown in Figure 11.

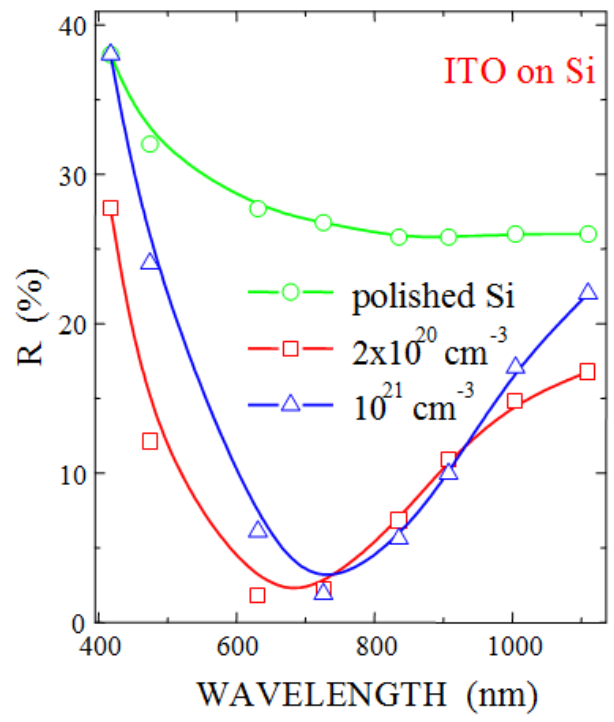

Figure 11. Antireflection action of the $80 \mathrm{~nm}$ ITO films for different carrier concentrations.

Metal to form an ohmic contact in the back side of the wafer was deposited on the $\mathrm{n}^{+}$-layer previously created by diffusion. The device area for measurements was $1-4 \mathrm{~cm}^{2}$. Approximately, a $1 \mu \mathrm{m} \mathrm{Cr} / \mathrm{Cu} / \mathrm{Cr}$ film was evaporated through a metal mask to make a grid pattern of approximately 10 grid lines/cm. After the fabrication, the capacitance-voltage characterization was conducted in order to control the value of the potential barrier. Then the following parameters were measured under $\mathrm{AMO}$ and $\mathrm{AM} 1.5$ illumination conditions using the solar simulator Spectrolab X25: open circuit voltage $V_{o c}$ short circuit current $I_{s c}$ fill factor FF, and efficiency. No attempt was made to optimize the cells for efficiency through a better collection grid. The series resistance $\left(R_{\mathrm{s}}\right)$ of the cell was measured using the relationship $R_{\mathrm{s}}=(V-$ $V_{o c)} I_{s c}$ [22], where $V$ is the voltage from the dark $I-V$ characteristic at that point where $I=I_{s c}$. More technological details can be found in [23]. 


\section{Properties of the solar cells}

The potential barrier height of the ITO/n-Si solar cells determined from the capacitance-voltage $(\mathrm{C}-\mathrm{V})$ characteristics is $0.9 \mathrm{eV}$. This high value of the potential barrier let us consider such structures as pseudo classical diffusion p-n junctions. Thus, it is possible to expect that the diffusion of holes in the silicon bulk is the main carrier transport mechanism instead of the thermo-ionic emission in the Schottky and the metal/tunnel oxide/semiconductor structures. Moreover, $\mathrm{C}-\mathrm{V}$ measurements of the potential barrier in structures with a created inversion layer deliver an incorrect the potential barrier [24]. The barrier determined with this method is lower than the actual value.

A straightforward measurement of the temperature dependence of the dark current is, in principle, sufficient to identify a bipolar device in which the thermo-ionic current is negligible compared to the minority-carrier diffusion current $J_{d}$ (in units of current density). Simple Shockley's analysis of the $p$ - $n$ diode with results for the temperature dependence of the silicon parameters (diffusion length, the diffusion coefficient, the minority carrier life-time, and the intrinsic concentration) [25] shows that

$$
J_{d}=J_{0 d} \exp [(q V / k T)-1]
$$

and

$$
J_{0 d} \propto T^{\gamma} \exp \left(-E_{g 0} / k T\right)
$$

where $\gamma=2.4$ and $E_{\mathrm{g} 0}=1.20 \mathrm{eV}$.

From Eq.(5) it can be seen that a plot of $\log \left(J_{0 \mathrm{~d}} / T^{\gamma}\right)$ versus $1 / \mathrm{T}$ should yield a straight line,

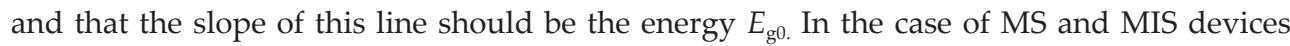
this slop must be equal to the value of the barrier $\varphi_{b}$. Usually, the series resistance of the device affects the $I-V$ characteristics at high forward current densities. To prevent this second order effect, we have to measure the $J_{\mathrm{sc}} \mathrm{vs} V_{\mathrm{oc}}$ dependence [22]. The photogenerated current is equal to the saturation photocurrent. For a minority-carrier MIS diode with a thin insulating layer [25]

$$
J_{s c}=J_{r g}\left(V_{o c}\right)+J_{d}\left(V_{o c}\right)
$$

As $J_{\mathrm{d}}$ increases more rapidly with bias than the recombination current density $J_{\mathrm{rg}}$ in the high illumination limit we should have

$$
J_{s c}=J_{0 d} \exp \left(q V_{o c} / n k T\right),
$$


where the $n$ factor is very close to 1 .

Figure 12 shows the measured dependence of $J_{\mathrm{sc}}$ on $V_{\mathrm{oc}}$ at room temperature. The value of $J_{\mathrm{od}}$ in (7) was determined by measuring $J_{\mathrm{sc}}$ and $V_{\mathrm{oc}}$ at different temperatures under illumination with a tungsten lamp. An optical filter was used to prevent the heating of the cell by the infra-red radiation. For each $J_{\mathrm{sc}}-V_{\mathrm{oc}}$ pair lying in the range where $n \approx 1$, the value $J_{0 \mathrm{~d}}=J_{02}$ was calculated from (7). After correction for the $T^{\gamma}$ factor appearing in Eq. (5), the $J_{0 \mathrm{~d}}$ values were plotted as a function of reciprocal temperature as shown in the insert of Figure 11.

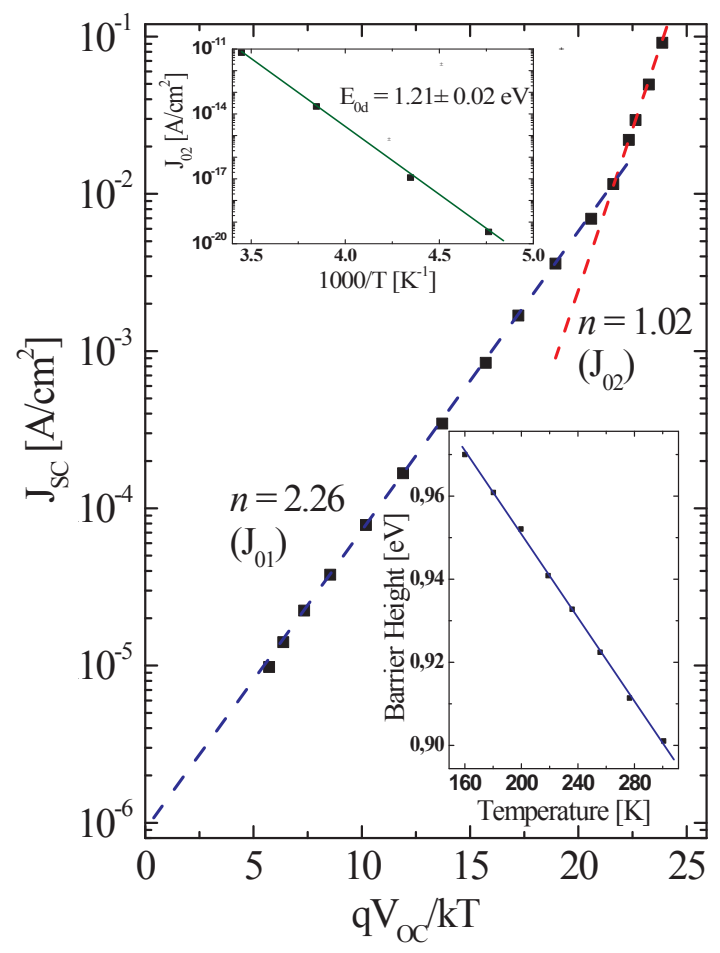

Figure 12. Measured dependence of $J_{s c}$ on $V_{o c}$ at room temperature and calculated dependence of the current density $J_{02}=J_{\text {Od }}$ under a high illumination level corrected for the $T^{v}$ factor as function of reciprocal temperature for ITO/n-Si solar cells. The dependence of the barrier height on temperature is also shown in the insert.

The slope of the $J_{02}$ vs $1 / T$ line was found to correspond to energy $E_{\mathrm{g} 0}$ from Eq. (5). It can be concluded that, for high current densities, the current in the cell is carried almost exclusively by holes injected from the ITO contact and diffusing into the base of the cell. Below we give other independent evidence of the diffusion mechanism. 
Output characteristics of the ITO/n-Si solar cell, measured under AM0 and AM1.5 illumination conditions, as well as the calculated dependence of the output power of the cell versus the photocurrent, are shown in Figure 13.

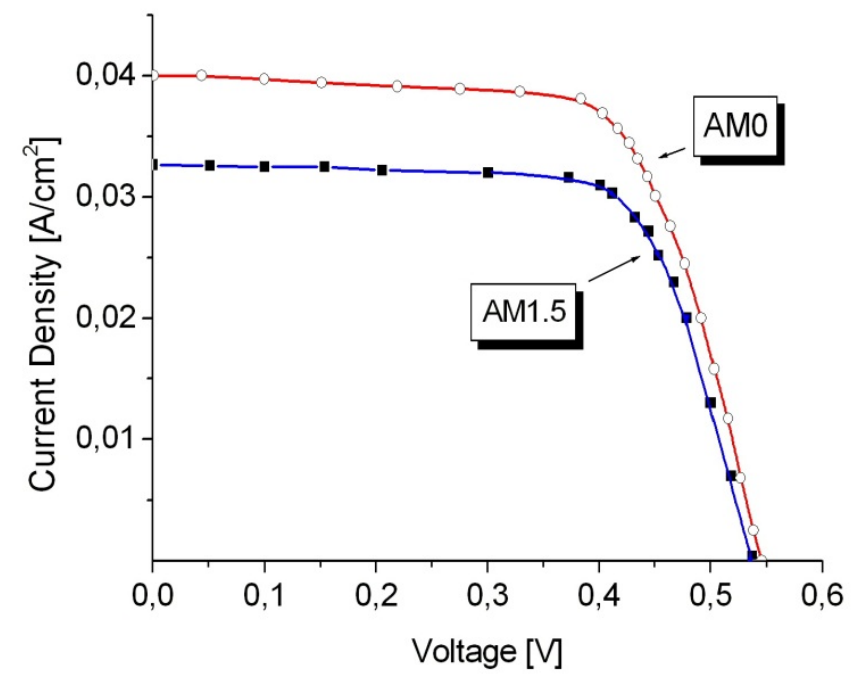

Figure 13. Loading I-V characteristics of the ITO/n-Si solar cell measured under AM0 and AM1.5 illumination conditions.

The fill factor (FF) and the efficiency calculated from these characteristics are 0.68 and $10.8 \%$ for AM0 illumination conditions, whereas they are 0.68 and $12.1 \%$ under the AM1.5 conditions.

We can observe that the parameters of the solar cells fabricated with the silicon wafers treated in hot SC-1 solutions, with an error of $\pm 10 \%$, coincide with those obtained using wafers treated in hot $\mathrm{H}_{2} \mathrm{O}_{2}$. At the same time, the parameters of the cells fabricated on wafers without these treatments, when the ITO film was deposited on the silicon wafer after a treatment in an HF solution, were significantly lower.

\section{Direct evidence of minority carrier injection in ITO-Si solar cells: Bipolar transistor}

Since the barrier height exceeds one half of the silicon energy band-gap, the formation of an inversion p-layer at the silicon surface is obvious. To avoid any speculations in this issue and to present the direct evidence of the existence of a minority (hole) carrier transport in ITO-nSi structures, a bipolar transistor structure was fabricated on a $10 \Omega$-cm monocrystal- 
line silicon substrate, in which the emitter and the collector areas were fabricated using ITO/n-Si junctions, and the ITO film was deposited by the spray technique described above followed by a photolithographic formation of the emitter and the collector areas. The silicon substrate followed the treatment in SC-1 or $\mathrm{H}_{2} \mathrm{O}_{2}$ solutions described above. An ohmic $\mathrm{n}^{+}-$ contact (a base) was formed by local diffusion of phosphorous in the silicon substrate. Figure 14 shows the dependence of the collector current versus the collector-base voltage using the emitter current as a parameter as well as the emitter injection efficiency of the ITO/n$\mathrm{Si} / \mathrm{ITO}$ transistor [26].

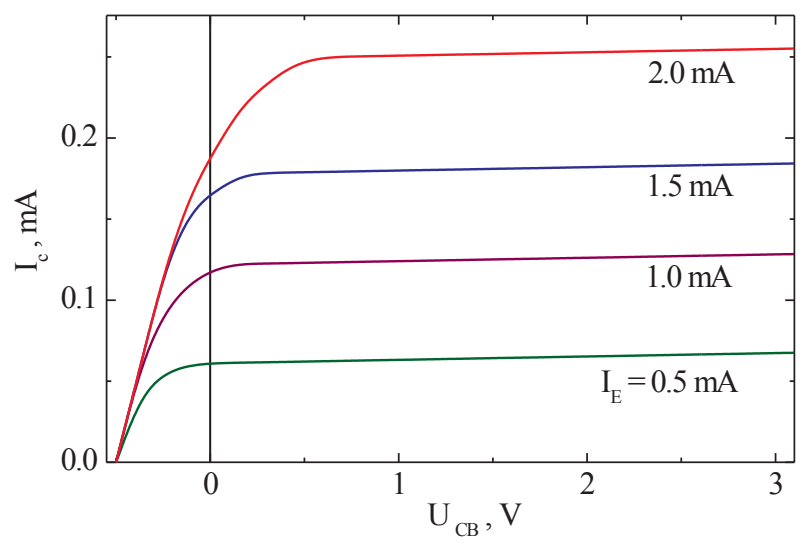

Figure 14. Dependence of the collector current versus the collector-base voltage (the emitter current is used as a parameter). The emitter injection efficiency of the ITO/n-Si/ITO transistor fabricated on a $10 \Omega$-cm silicon substrate is also shown.

Thus, we obtained an efficiency of 0.2-0.3 even for a non-optimized long base transistor. This makes an obvious evidence of the existence of an inversion layer formed in the ITO/nSi structures with a barrier height of $0.9 \mathrm{eV}$. We can also compare our results with the first bipolar transistor based on germanium, in which the existence of an inversion layer on the germanium surface determined a high injection level of minority carriers. In metal-semiconductor contacts, operated as majority carriers' devices, and described by the Schottky theory, the injection ratio does not exceed the value of $10^{-4}$. Thus, based on such unipolarity, the fabrication of the bipolar transistor is impossible.

\section{Radiation emission from ITO-nSi structures}

Figure 15 shows the radiation emission obtained from the ITO/n-Si structures under forward bias [26]. 


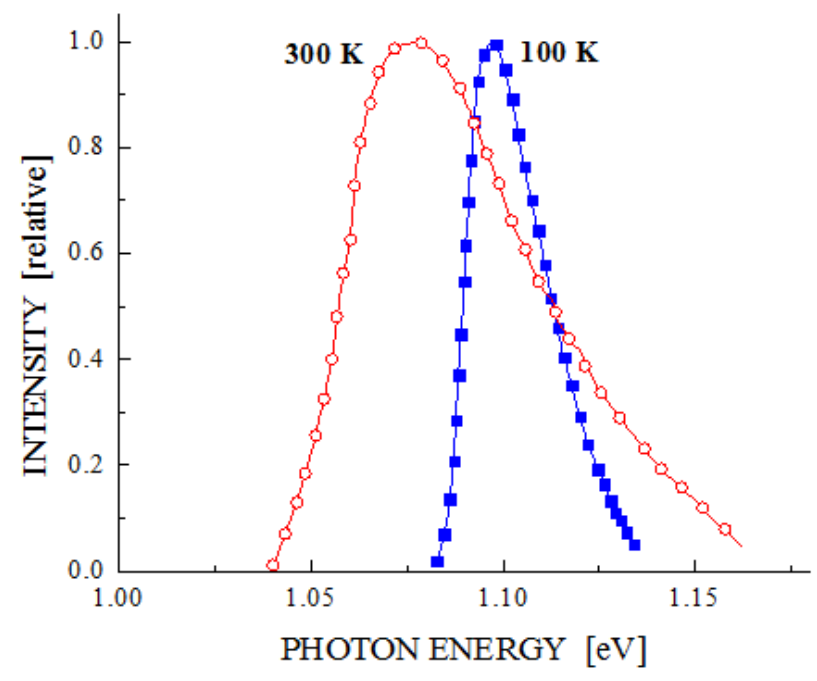

Figure 15. Normalized electroluminescence spectra obtained from an ITO/n-Si structure.

The pumping current density is $500 \mathrm{~A} / \mathrm{cm}^{2}$.

An intense luminescence was observed from the ITO/n-Si structures. Estimations give an internal quantum efficiency of about $10^{-4}$. This is only possible for the case of a high value of the injection coefficient of minority carriers.

\section{Minority-carrier injection ratio}

The minority-carrier injection ratio or injection coefficient $\gamma$ is defined as $\gamma=\frac{J_{p}}{J_{p}+J_{n}}$

where $J_{p}$ is the hole injection current and $J_{n}$ is the majority-carrier contribution to the forward-biased current in a Schottky barrier.

According to [27]:

$$
J_{p}=\frac{q D_{p} p_{n 0}}{L_{p}}\left[\exp \left(\frac{q V}{k T}\right)-1\right],
$$

where $p_{n 0}$ is the equilibrium hole concentration in the neutral $n$-region, $D_{p}$ is the diffusion coefficient, $L_{p}$ is the diffusion length for holes, and $V$ is the applied forward voltage.

Taking into account that $p_{n 0}=n_{i}^{2} / N_{d}$ where $n_{i}$ is the intrinsic concentration given by 


$$
n_{i}=\left(N_{c} N_{v}\right)^{1 / 2} \exp \left(-\frac{E_{g}}{2 k T}\right)
$$

with $N_{c}, N_{v}$ being the effective density of states in the conduction and valence bands, respectively, and $E_{g}$ is the energy gap. Taking into account that $L_{p}=\left(D_{p} \tau_{p}\right)^{1 / 2}, D_{p}=k T \mu_{p} / q$, where $\tau_{p}$ is the lifetime of holes in the $n$ region, $\mu_{p}$ the hole mobility in this region, and introducing the term $\operatorname{csch}\left(\frac{W_{b}}{L_{p}}\right)$ where $W_{b}$ is the n-base width, for $V \gg>k T / q$ Eq. (8) can be rewritten,

$$
J_{p} \cong \frac{q D_{p}^{1 / 2} N_{c} N_{v}}{\tau_{p}^{1 / 2} N_{d}} \exp \left(\frac{q V-E_{g}}{k T}\right) \operatorname{csch}\left(\frac{W_{b}}{L_{p}}\right)
$$

The majority-carrier current is

$$
J_{n}=A^{*} T^{2} \exp \left(-\frac{q \phi_{b}}{k T}\right)\left[\exp \left(\frac{q V}{k T}\right)-1\right]
$$

where $A^{*}$ is the modified Richardson constant and $\varphi_{b}$ is the barrier height.

From (10) and (11)

$$
\gamma=\frac{J_{p}}{J_{p}+J_{n}}=\left[1+\frac{A^{*} T^{2} L_{p} N_{d}}{q D_{p} N_{c} N_{v} \operatorname{csch}\left(\frac{W_{b}}{L_{p}}\right)} \exp \left(\frac{E_{g}-q \phi_{b}}{k T}\right)\right]^{-1} .
$$

Using (12) we try to find out the value of the barrier height for the case of our ITO-nSi solar cells $\left(N_{d}=5 \times 10^{14} \mathrm{~cm}^{-3}, L_{p}=0.4 \mathrm{~mm}\right)$ that fit to the experimentally obtained value; in this case it was $1.03 \mathrm{~V}$ (Figure 16).

Thus, from the experimental data and theoretical estimations the barrier height in ITO-nSi structures is very high and due to the strong inversion condition at the surface of n-silicon.

As the next step, we will explain this phenomenological fact correlating our experimental and estimated results. 


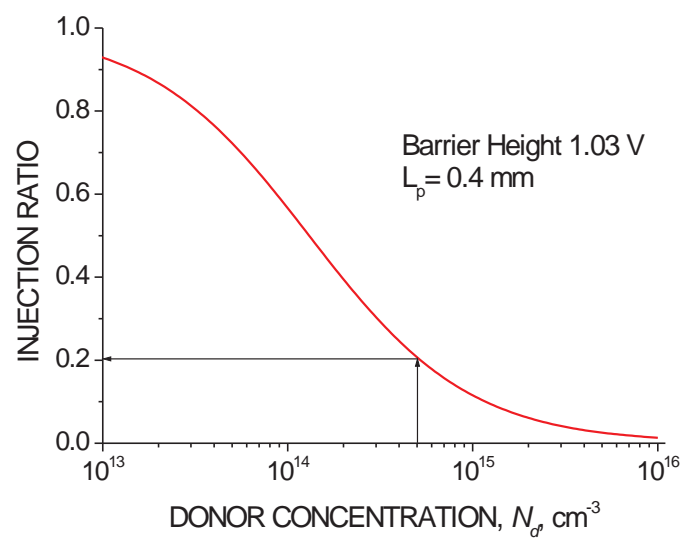

Figure 16. Dependence of the injection ratio on the donor concentration calculated using equation (12) for a barrier height of $1.03 \mathrm{~V}$ and a diffusion length of $0.4 \mathrm{~mm}$.

\section{Physical model of spray deposited ITO/n-Si solar cells}

For this purpose, we have to take into account the following remarks:

1. The thin insulating layer formed at the silicon surface after boiling it in SC-1 or hydrogen-peroxide $\left(\mathrm{H}_{2} \mathrm{O}_{2}\right)$ solutions is very thin, about $0.8-1 \mathrm{~nm}$ [4-8], and presents negative charge [4]. The thickness of this layer according to [28] can be also $0.68 \mathrm{~nm}$.

2. Below this thickness, there is no limit for the electron flow from the n-type silicon substrate due to the tunnel effect.

3. An additional negative charge can be present at either, the silicon surface or the insulating layer, due to the $\mathrm{Al} /$ or Fe contamination introduced during the boiling of the wafers in SC-1 or in the hydrogen-peroxide $\left(\mathrm{H}_{2} \mathrm{O}_{2}\right)$ solutions. The origin of this contamination can be the use of non-highly purified $\mathrm{H}_{2} \mathrm{O}_{2}$ or the dissolving of the Pyrex glass wall of the container by $\mathrm{NH}_{4} \mathrm{OH}$.

4. The band banding due to this inversion condition is formed at the silicon surface after the chemical treatment using either, SC-1 or hydrogen-peroxide $\left(\mathrm{H}_{2} \mathrm{O}_{2}\right)$ solutions, before the ITO film deposition by spray pyrolysis. Based on published data $[9,10]$, the surface potential (diffusion potential) in the $n$-Si $10 \Omega$-cm due to acceptor-like surface states can be as high as $0.75 \mathrm{eV}$ how is shown in Figure 2, if the negative charge $8 \times 10^{-8} \mathrm{C} / \mathrm{cm}^{2}$ is located near the silicon surface.

5. The work function of the ITO films is $4.8 \mathrm{eV}$ [13]. 
Below, by using Figure 17, we demonstrate the formation of the ITO-nSi structure in two stages. First, after the boiling in SC-1 or hydrogen-peroxide $\left(\mathrm{H}_{2} \mathrm{O}_{2}\right)$ solutions, the inversion layer at the silicon surface is formed due to acceptor-like surface states (negative charge due to trapped electrons from the conducting band of the silicon); after the ITO film deposition, and due to the fact that $q \phi_{\text {IтО }}<q \chi_{s}+\left(E_{g}-\Delta\right)$, some electrons coming from the conduction band of the ITO film, fill non-occupied surface states levels above the semiconductor Fermi level. When the Fermi levels of the ITO and the Si coincide for thermal equilibrium, the value of $\Delta$ decreases and the value of the potential barrier $q \phi_{b}$ increases. This leads to a stronger inversion band bending at the silicon surface due to the increasing surface negative charge.

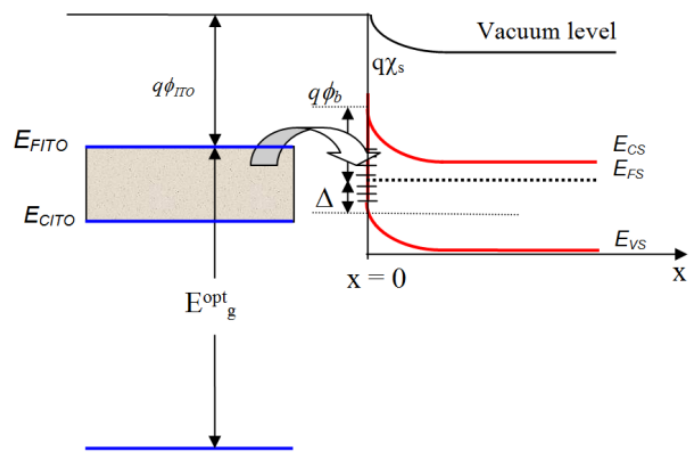

Figure 17. Formation of the inversion layer in the ITO-nSi structure when the ITO film is deposited on the silicon surface with surface barrier $q \phi_{b}$.

Second, consider the energy band diagram of the ITO-nSi solar cells with an inversion surface layer is shown in Figure 18. Our estimation based on the injection ratio gives a barrier height of $q \phi_{b}=1.03 \mathrm{eV}$. Thus a $\mathrm{p}^{+}$-inversion layer is formed at the silicon surface.

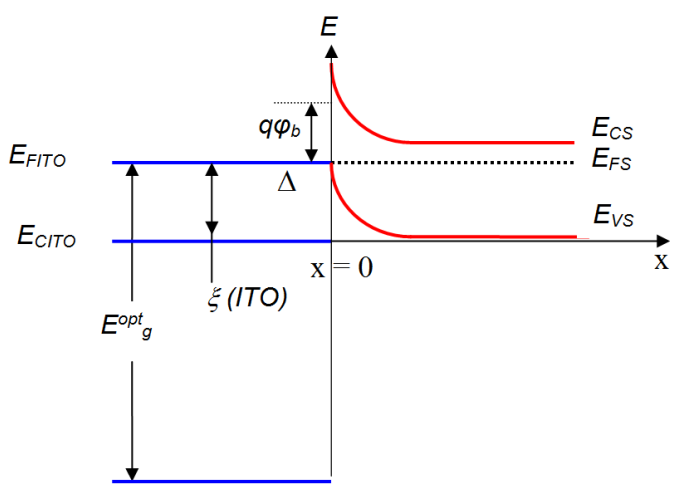

Figure 18. Energy band diagram of the ITO/n-Si solar cells with an inverted surface. 
The role of the ITO film is to create an ohmic contact with the $p$--inversion layer. Furthermore, this film serves as a supplier of holes for the inversion layer. Because of the short distance $(\sim 0.1$ $\mathrm{eV})$ existing between the top of the silicon valence band $\left(E_{v s}\right)$ and the Fermi level ( $\left.E_{\text {FITO }}\right)$ of the ITO film, the number of empty states below the Fermi level in ITO is about $10^{19} \mathrm{~cm}^{-3}$ [29].

\section{Waste-free solar modules}

Usually solar cells have a rectangular form and are obtained by cutting them from a circular silicon wafer, given place to a waste of about $41 \%$. We propose a different geometrical approach allowing for the fabrication of circular modules without the waste of silicon. First, the silicon cell fabricated using round wafer is cut in sectors as shown in Figure 19.

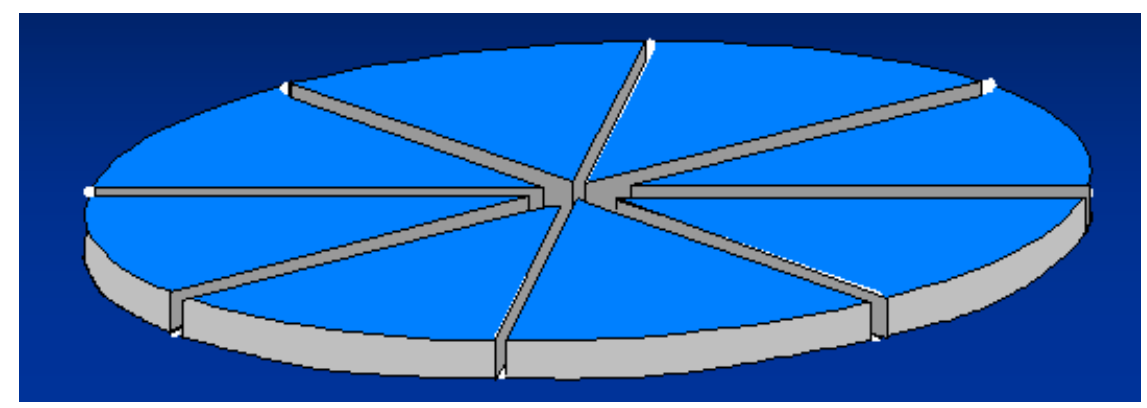

Figure 19. A round solar cell cut in sectors for circular packaging.

Then, the cut sectors are mounted on a plastic base and connected in series. The base has two output electrical contacts. After that, a transparent relief plastic cover is hermetically connected with the base of the module. Solar modules with a rectangular shape can be assembled from sliced solar cells as shown in Figure 20.

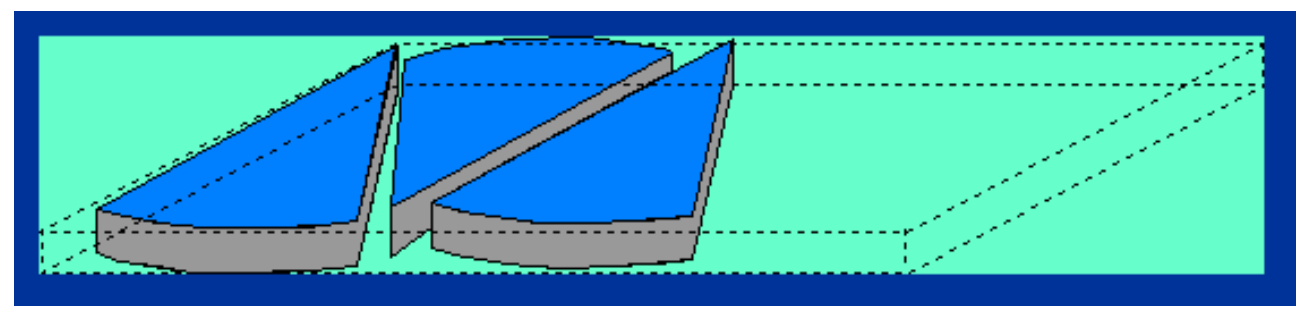

Figure 20. Arrangement of sliced solar cells for rectangular packaging.

Example of waste-free solar modules fabricated on 3 inch silicon wafers is shown in Figure 21. 


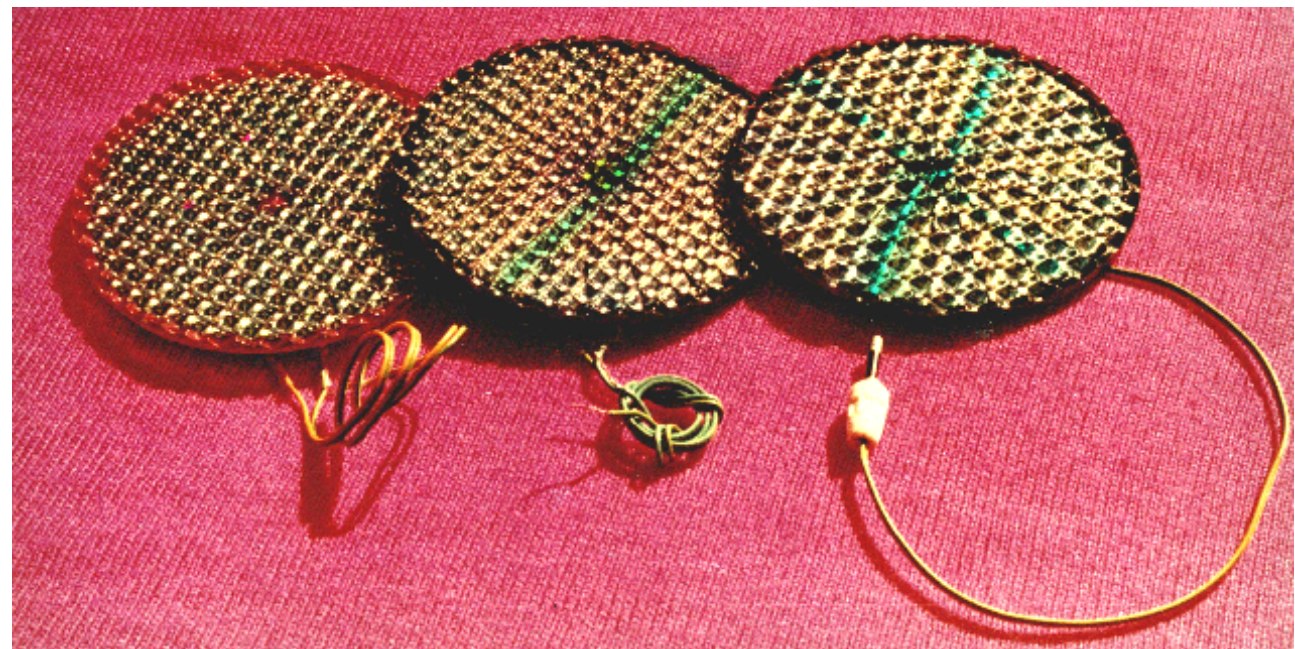

Figure 21. ITO-nSi portable sector-shaped solar modules fabricated by waste-free technology on 3 inch silicon wafers. Each module is assembled from 20 solar cells connected in serial.

The parameters of these modules (under AM1.5 irradiation) are:

Open circuit voltage $=10.8 \mathrm{~V}$;

Short circuit current $=72 \mathrm{~mA}$;

Fill factor $=0.7$ :

Efficiency $=12 \%$.

Using silicon wafers of different diameters, modules with different output parameters can be fabricated. For instance, the module fabricated from a $20 \mathrm{~cm}$ diameter silicon wafer cut in 20 sector-shaped solar cells will have an output of $0.5 \mathrm{~A}$ and $10.8 \mathrm{~V}$, and a power of 3.8 Watt. Such hermetic modules can be easily assembled in a solar panel without waste of silicon.

\section{Conclusions}

We discussed some new physical aspects presented by spray deposited ITO-nSi solar cells which are tightly connected with the fabrication technology. It was shown that certain chemical treatment of the silicon wafers in alkaline-peroxide solutions gives rise to the formation of a very thin (0.6-1 nm) insulating layer on the silicon surface. Moreover, a high negative charge, due to acceptor-like surface levels after such chemical treatment, creates a surface $p+$ inversion layer, which leads to a high potential barrier at the silicon surface. After the deposition of the ITO film on the silicon surface, this barrier increases up to $1 \mathrm{eV}$ due to the filling of empty surface states above the silicon Fermi level by electrons coming from the 
ITO film. The estimated barrier height agrees very well with the experimentally found value of the minority-carrier injection ratio. A model of the ITO/n-Si solar cells based on the induced surface inversion layer originated by chemical treatments, explains perfectly the transistor effect observed in ITO-nSi-ITO structures, as well as the high level radiation emission from ITO/n-Si devices.

Solar cells based on ITO/n-Si structures are promising for solar energy conversion due to their relativity high output parameters and a low cost fabrication process. Such technological processes are cheap because the lack of high-temperature diffusion processes. Cells with low output parameters after etching of the ITO layer can be used again for an additional solar cells fabrication. We also showed a new waste-free design of solar modules, circular and rectangular, with $40 \%$ economy of silicon. Such approach can be successfully applied to any type of solar cells.

\section{Author details}

Oleksandr Malik* and F. Javier De la Hidalga-W

*Address all correspondence to: amalik@inaoep.mx

Instituto Nacional de Astrofísica, Óptica y Electrónica (INAOE), Puebla, Mexico

\section{References}

[1] Malik O., De la Hidalga-W F.J., Efficient Silicon Solar Cells Fabricated with a Low Cost Spray Technique. In: Rugescu R. (ed.) Solar Energy. Rijeca: InTech; 2010. p. 81-104.

[2] Shewchun J, Buró D, Spitzer M. MIS and SIS Solar Cells. IEEE Trans. Electron Devices, 1980; ED-27(4) 705-715.

[3] Daw A, Datta A, Ash M. On the Open-Circuit Voltage of a Schottky-Barrier MIS Solar Cell. Solid-State Electronics, 1982; 25(12) 1205-1206.

[4] Angermann H. Passivation of Structured P-Type Silicon Interfaces: Effect of Surface Morphology and Wet-Chemical Pre-Treatment. Applied Surface Science, 2008; 254 8067-8074.

[5] Bertagna V et al. Electrochemical Impedance Spectroscopy as a Probe for Wet Chemical Silicon Oxide Characterization. J. Solid State Electrochem, 2001; 5 306-312.

[6] Bertagna V et al. Electrochemistry, a Powerful Tool for the Investigation of the Nanoscale Processes at Silicon Surface. J. of New Materials for Electrochemical Systems. 2006; 9 277-282. 
[7] Neuwald U. Chemical Oxidation of Hydrogen Passivated Si (111) Surfaces in $\mathrm{H}_{2} \mathrm{O}_{2}$. J. Appl. Phys., 1995; 78(6) 4131-4136.

[8] Verhaverbeke S, Parker J, McConnell. The Role of $\mathrm{HO}_{2}^{-}$in SC-1 Cleaning Solutions. In: Material Research Symposium Proceeding. 1997; 477 47-56.

[9] Munaka C, Shimizu H. Aluminium-Induced AC Surface Photovoltages in N-Type Silicon Wafers. Semicond. Sci. Technol., 1990; 5 991-993.

[10] Shimizu H, Shin R, Ikeda M. Quantitative Estimation of the Metal-Induced Negative Charge Density in N-Type Silicon Wafers From Measurements of Frequency-Depended AC Surface Photovoltage. Jpn. J. Appl. Phys., 2006; 45 1471-1476.

[11] Pan C, Ma T. Work Function of $\operatorname{In}_{2} \mathrm{O}_{3}$ Film as Determined From Internal Photoemission. Appl. Phys. Letters, 1980; 37 714-716.

[12] Ginley D., editor. Handbook of Transparent Conductors. New York: Springer; 2010.

[13] Nakasa A. et al. Increase in the Conductivity and Work Function of Pyrosol Indium Tin Oxide by Infrared Irradiation. Thin Solid Films, 2005; 484(1-2) 272-277.

[14] Sato Y, et al. Carrier Density Dependence of Optical Band Gap and Work Function in Sn-Doped $\operatorname{In}_{2} \mathrm{O}_{3}$ Films, Applied Physics Express, 2010; 3 061101-1/3.

[15] Gouskov L, et al. Sprayed indium tin oxide layers: Optical parameters in the near-IR and evaluation of performance as a transparent antireflecting and conducting coating on $\mathrm{GaSb}$ or $\mathrm{Ga}_{1-\mathrm{x}} \mathrm{Al}_{\mathrm{x}} \mathrm{Sb}$ for IR photodetection. Thin Solid Films, 1983; 99 (4) 365-369.

[16] Vasu V, Subrahmanyam, A. Reaction kinetics of the formation of indium tin oxide films grown by spray pyrolysis. Thin Solid Films, 1990; 193-194 (2) 696-703.

[17] Manifacier J, Fillard J, Bind J. Deposition of $\mathrm{In}_{2} \mathrm{O}_{3}-\mathrm{SnO}_{2}$ layers on glass substrates using a spraying method. Thin Solid Films, 1981; 77(1-3) 67-80.

[18] Saxena A, et al. Thickness dependence of the electrical and structural properties of $\mathrm{In}_{2} \mathrm{O}_{3}:$ Sn films, Thin Solid Films, 1984; 117(2) 95-100.

[19] Theuwissen A, Declerck G. Optical and electrical properties of reactively d. c. magnetron-sputtered $\mathrm{In}_{2} \mathrm{O}_{3}$ : Sn films. Thin Solid Films, 1984; 121(2) 109-119.

[20] Nath P, Bunshah R. Preparation of $\operatorname{In}_{2} \mathrm{O}_{3}$ and tin-doped $\operatorname{In}_{2} \mathrm{O}_{3}$ films by novel activated reactive evaporation technique. Thin Solid Films, 1980; 69(1) 63-68.

[21] Haacke J. New figure of merit for transparent conductors. J. Appl. Phys., 1976; 47 4086- 4089.

[22] Rajkanan K, Shewchun J. A better approach to the evaluation of the series resistance of solar cells. Sol. St. Electron., 1979; 22(2) 193-197.

[23] Malik O, De la Hidalga-W, F.J., Zúñiga-I C, Ruiz-T G. Efficient ITO-Si solar cells and power modules fabricated with a low temperature technology: results and perspectives. J. Non-Cryst. Sol., 2008; 354 2472-2477. 
[24] Rhoderick E.H. Metal-semiconductor contacts. Oxford: Clarendon Press; 1978.

[25] Tarr N, Pulfrey D. New experimental evidence for minority-carrier MIS diodes. Appl. Phys. Lett., 1979; 34(4) 295-297.

[26] Malik O, Grimalsky V, Torres-J A, De la Hidalga-W F.J., Room Temperature Electroluminescence from Metal Oxide-Silicon. In: Proceedings of the $16^{\text {th }}$ International Conference on Microelectronics, ICM 2004, December 06-08, Tunisia, Tunis, 471-474.

[27] Buchanan D, Card H. On the Dark Currents in Germanium Schottky-Barrier Photodetectors. IEEE Trans. On Electron Devices, 1982; ED-29(1) 154-157.

[28] Petitdidier S. et al. Growth mechanism and characterization of chemical oxide films produced in peroxide mixtures on Si (100) surfaces. Thin Solid Films, 2005; 476 5158.

[29] Malik O, Grimalsky V, De la Hidalga-W F.J. Spray deposited heavy doped indium oxide films as an efficient hole supplier in silicon light-emitting diodes. J. Non-Cryst. Sol., 2006; 352 1461-1465. 